\title{
The tale of two lakes: managing lake degradation, Rotorua lakes, New Zealand
}

\author{
P. Scholes ${ }^{1} \&$ J. McIntosh ${ }^{2}$ \\ ${ }^{1}$ Environment Bay of Plenty, New Zealand \\ ${ }^{2}$ Lochmoigh Limited, New Zealand
}

\begin{abstract}
Lakes Rotorua and Rotoiti, two co-joined lakes of the Rotorua Group, North Island, New Zealand, have had an increasing prevalence of cyanobacterial blooms due to lake eutrophication. Targets for water quality restoration are set in statutory planning objectives expressed quantitatively by trophic level indices. Quantification of external and internal nutrient loads underpins the restoration targets. Comprehensive stream and groundwater monitoring, together with a monthly lake monitoring programme, provide data for models that delineate nitrogen inputs from sub-catchments to lake ecological modelling. Lake Rotorua catchment is dominated by pastoral land use and receives significant nitrogen $(\mathrm{N})$ and phosphorous (P) load from groundwater, as well as geothermal springs. Increasing groundwater nitrogen (predominantly as nitrate) and internal phosphorus loads need to be reduced to meet water quality objectives. Reduction of the external nutrient loads to Lake Rotorua has begun by addressing several sources. These include: the Rotorua City wastewater treatment plant upgrade; stream dosing with aluminium sulphate; areas with on-site wastewater treatment reticulated to the central wastewater treatment plant; and stormwater upgrades. Hydrological and limnological studies have found nutrient inputs to Lake Rotoiti to be dominated by the inflow from Lake Rotorua, which accounts for approximately $73 \% \mathrm{~N}$ and $76 \% \mathrm{P}$. A diversion wall has been installed to interrupt the underflow current from Lake Rotorua to Lake Rotoiti with Lake Rotorua waters deflected straight to the Lake Rotoiti outlet. The diversion wall has resulted in significant water quality gains for Lake Rotoiti. In this paper we explore strategies to improve lake water quality as part of an integrated land and water management programme, and how this led to the building of a diversion wall. We examine the steps taken to implement restoration works and explore
\end{abstract}


research into sediment capping, dredging and chemical treatments as some of the remediation options to address Lake Rotorua's internal nutrients.

Keywords: action plans, trophic level index, eutrophication.

\section{Introduction}

Lakes Rotorua and Rotoiti form the second largest lake complex in the North Island of New Zealand. Lying in an area known as the Taupo Volcanic Zone, the lakes were formed from two separate eruption events. Lake Rotorua was formed from an ignimbrite caldera over 200,000 years ago [1] and is a shallow lake with a maximum depth of 45 metres, an average depth of 11 meters, and a surface area of $79.8 \mathrm{~km}^{2}$. The more recently formed Lake Rotoiti was created in the Haroharo caldera by a lava dam around 8,500 years ago. Lake Rotoiti has a surface area of $33.5 \mathrm{~km}^{2}$ with a maximum depth of 125 metres, and an average depth of 31.5 metres.

The $508 \mathrm{~km}^{2}$ catchment of Lake Rotorua is dominated by pastoral land use (52\%) followed by indigenous vegetation $(25 \%)$ and exotic forest $(14 \%)$. Lake Rotoiti's $124 \mathrm{~km}^{2}$ catchment has less pastoral land use (16\%) and is predominantly exotic forest (46\%) and indigenous forest (36\%) [13]. Up until the 1870 s most of the catchments were covered by indigenous forest, which was subsequently clear felled. Some areas were established with Pinus radiata plantation forests, with sheep and beef and dairy farming remaining small scale until the 1940s, when mineral deficiencies were corrected with mineral amended fertilizers. Urban areas expanded, particularly around the lake fringes, and until 1991 treated wastewater was discharged to Lake Rotorua, but is now irrigated in forest plantations.

Lake Rotorua is polymictic with an annual mean total nitrogen (TN) and total phosphorus (TP) concentrations of $0.408 \mathrm{mg} \mathrm{L}^{-1}$ and $0.034 \mathrm{mg} \mathrm{L}^{-1}(2008 / 2009)$ [13], respectively. There are nine major inflows contributing over $288 \mathrm{t} \mathrm{yr}^{-1} \mathrm{TN}$ and $21.6 \mathrm{t} \mathrm{yr}^{-1} \mathrm{TP}$ as well as $131 \mathrm{t} \mathrm{yr}^{-1} \mathrm{TN}$ and $8 . \mathrm{t} \mathrm{yr}^{-1} \mathrm{TP}$ from minor streams, springs and groundwater [3].

Stratifying from October to May, monomictic Lake Rotoiti's major inflow is from the Ohau Channel (fig 1) carrying around $259 \mathrm{t} \mathrm{yr}^{-1} \mathrm{TN}$ and $31.1 \mathrm{t} \mathrm{yr}^{-1} \mathrm{TP}$. An estimated $73 \% \mathrm{TN}$ and $76 \% \mathrm{TP}$ was entering the lake, the surplus carried down the Kaituna River at the lake outlet (fig. 1). Minor inflows contribute approximately $110 \mathrm{t} \mathrm{yr}^{-1} \mathrm{TN}$ and $4 \mathrm{t} \mathrm{yr}^{-1} \mathrm{TP}$, although recent monitoring shows this may be higher. Much of the nitrogen comes from elevated ammonium $\left(\mathrm{NH}_{4}-\right.$ $\mathrm{N})$ concentrations in geothermal inflows.

Degradation of Lakes Rotorua and Rotoiti were recognised as occurring since the early 1970s. Intensification of pastoral farming systems and increasing urban populations have exacerbated eutrophication problems amplifying calls for further action to arrest lake water quality deterioration.

Local government bodies together with the local Maori indigenous tribe (iwi), Te Arawa, and local stakeholders have instigated an integrated programme of land and water management, the Rotorua Lakes Restoration Programme. This paper examines the processes and results the Restoration Programme has had on 


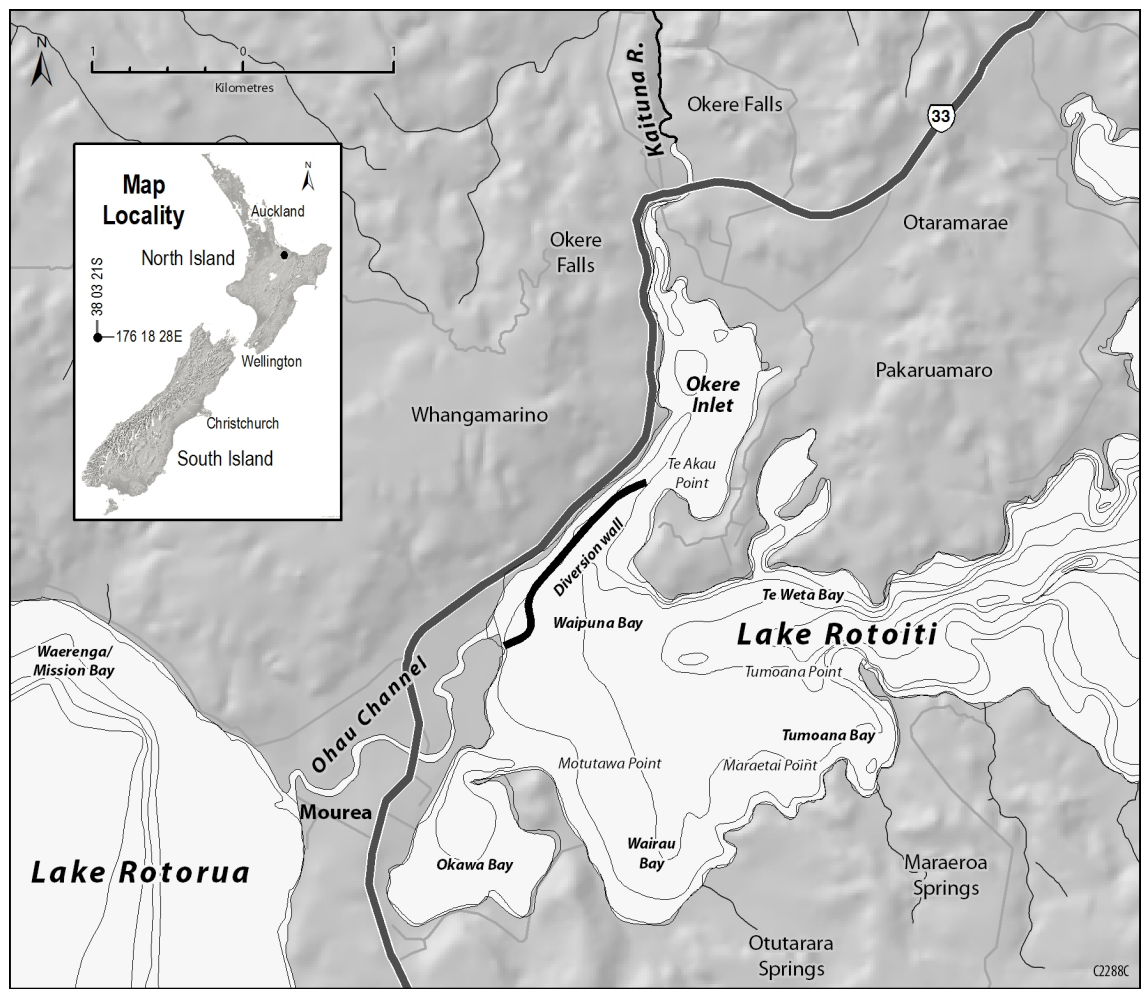

Figure 1: Map of Lakes Rotorua and Rotoiti showing the location of the Ohau Channel, Kaituna River and the diversion wall.

Lakes Rotorua and Rotoiti and focuses on recent remediation works for the lakes.

\section{A plan of action}

Environment Bay of Plenty Regional Council (EnvBOP) and Rotorua District Council (RDC) are the two local government agencies charged with implementing the principles of the Resource Management Act (1991, RMA), the overarching legislation guiding the sustainable management of natural and physical resources in New Zealand. The RMA charges Regional Councils with developing regional plans which describe issues, and set objectives, methods and rules for sustainable water and land management. The Regional Water and Land Plan (W\&LP) has its objectives set by the community in a consultative process and these objectives provide the structure for the Rotorua Lakes Restoration Programme.

Each of the twelve Rotorua lakes has a trophic level index (TLI) set as an objective in the W\&LP which forms the basis for developing nutrient reduction targets to protect and restore water quality. EnvBOP calculates a TLI for each 
lake annually using the annual average of four key parameters: TN, TP, chlorophyll a (Chla), and Secchi depth (SD) using the protocols described by Burns et al. (2000) [2].

Lakes that don't meet their TLI objective trigger a public process for development of a strategy to arrest nutrient pollution and return the lake to its objective TLI. Strategies formulated in consultation with the wider community and stakeholders, help the community to gain an understanding of basic limnology and issues contributing to lake eutrophication.

Focus groups have been developed with wide community representation and have been challenged to find solutions to the many issues giving rise to lake eutrophication. These groups identify gaps in the science and decision making and feedback to an Action Plan Working Party made up of key stakeholders which is overseen by a Rotorua Lakes Strategy Group. The Working Party develops recommended actions to achieve the long term water quality objectives based on guidance and recommendations of focus groups and under the advice from scientists brought together as Technical Advisory Groups (TAGs). An Action Plan is then formulated which synthesises the information gained from the councils, iwi, scientific and local communities; identifies and quantifies the source and magnitude of nutrient inputs; and specifies key recommendations for improving lake water quality.

In defining nutrient reduction targets at sustainable levels of nutrient input to maintain the lake's W\&LP TLI objective, N and P loads have been obtained by various methods. Initially $\mathrm{N}$ and $\mathrm{P}$ inputs are estimated based on land use area and land use loss coefficients ( $\left.\mathrm{kg} \mathrm{N}, \mathrm{P} \mathrm{ha}{ }^{-1} \mathrm{yr}^{-1}\right)$. Nutrient loss coefficients can be used to develop annual mass balance models which in turn can be used to predict the effect of external load changes on lake nutrient concentrations [12]. Hoare [9] used the Vollenweider [15] model related to the outflow concentration, C (also assumed to be the lake annual average concentration, $\mathrm{mg} \mathrm{m}^{-3}$ ), the annual nutrient load, $\mathrm{M}\left(\mathrm{mg} \mathrm{yr}^{-1}\right)$, and the annual outflow volume, $\mathrm{Q}\left(\mathrm{m}^{3} \mathrm{yr}^{-1}\right)$; where the retention coefficient, $\mathrm{R}$ (dimensionless), is the proportion of the external load retained within the lake; which is rearranged to estimate nutrient load:

$$
\mathrm{M}=\mathrm{CQ} /(1-\mathrm{R})
$$

Nurnberg [11] has shown $\mathrm{R}$ to be inversely related to hydraulic loading $\mathrm{Q} / \mathrm{A}$, where $A$ is the lake surface area. For Lake Rotorua ' $R$ ' is between 0.6 and 0.7 [12].

Defining nutrient targets and strategic actions in an Action Plan has paved the way for funding to be allocated from central government to boost local government funding for the implementation of actions.

\section{Implementing actions}

\subsection{Lake Rotoiti diversion wall}

The Rotorua-Rotoiti Action Plan states that to meet the Lake Rotoiti TLI objective of 3.5 TLI units a nitrogen reduction of $130 \mathrm{t} \mathrm{yr}^{-1}$ and $19 \mathrm{t} \mathrm{yr}^{-1}$ of 
phosphorous is required [3]. Throughout the Action Plan development phase several options were examined to help meet this nutrient reduction target concentrating on the Ohau Channel as the single largest source of nutrients and water to Lake Rotoiti.

Piping the flow directly to the Kaituna River (the natural outflow of Lake Rotoiti) was initially looked at but was discounted because of cost and cultural reasons.

Based on a study of particulate nutrient levels on the shallow shelf of Lake Rotorua before entry to the Ohau Channel by Gibbs [4], it was postulated that extending groynes from either side of the channel entrance out into the lake could reduce the amount of particulate material carried down the Ohau Channel. EnvBOP commissioned NIWA to study the potential nutrient reduction to be gained by erection of such a structure and impacts on lake morphology, circulation and sediment. Numerical modelling of hydrodynamics, waves and sediment transport, water sampling and analysis was part of a multi-faceted approach taken to studying particulate nutrient pathways to the Ohau Channel and the processes that cause their mobilisation [6].

Wave gauges and current meters as well as concentration profiles were measured perpendicular to the shore across the shallow shelf offshore of the Ohau Channel entrance. An analytical sediment resuspension model coupled with a wind-wave generation model (SWAN) and a hydrodynamic flow model (MIKE21) were used to relate wind impacts on wave height and water movement.

A number of sediment transport scenarios were performed using variable wind conditions with and without $200 \mathrm{~m}$ and $400 \mathrm{~m}$ long groynes extending into Lake Rotorua. The best modelling scenario estimated a reduction of about $15 \%$ of the total volatile (organic) suspended load with the $200 \mathrm{~m}$ groyne, which relates to a similar reduction in nitrogen and phosphorus. Inorganic sediment was found to be reduced by around $70 \%$, but the groynes would have no impact on the dissolved nutrient load.

Overall the modelling of groynes showed that the potential gains in nutrient reduction may not be large enough to be economically practicable and other options should be explored.

The nature of the connection between Ohau Channel and Lake Rotoiti had been established by intensive monitoring in 1985-86. Warmer summer inflows are less dense than lake water and remain on the surface as discrete overflow, mostly short-circuiting to the Kaituna River. Winter and spring inflows are colder and denser than lake water. These flow eastward initially as an underflow current travelling along the bottom of the lake to the deeper eastern basin. Due to seasonal temperature differences, the underflow can insert as an intrusion layer driven by the hydraulic inertia of the density current [6]. Diurnal variation in temperature can also result in the density current switching from an underflow to an interflow.

Limnological and water quality surveys indicated that greater than $70 \%$ of the $\mathrm{N}$ and $\mathrm{P}$ flowing into Lake Rotoiti comes via the Ohau Channel [6]. Inflow from the Ohau Channel enters at an average $15 \mathrm{~m}^{3} \mathrm{~s}^{-1}$ but reaches up to $70 \mathrm{~m}^{3} \mathrm{~s}^{-1}$ as it 
entrains lake water distributing nutrients throughout the lake with the winter mixing event.

The proximity of the Kaituna River outlet to the Ohau Channel inflow lends itself to installation of a diversion structure to eliminate nutrient input to Lake Rotoiti. Gibbs et al. [6] estimated a diversion could reduce annual N and P loads by 181 tonnes and 25 tonnes respectively. A diversion while reducing nutrients and algal inoculum would reduce oxygen delivery and the lakes flushing rate. Average residence time is predicted to increase from 2.4 years to 6.3 years which could benefit water quality with increased sedimentation and denitrification.

Based on the limnological information gathered and boosted by biofish (a depth changing conductivity-temperature datalogger) monitoring of Lakes Rotorua and Rotoiti, a collaborative effort by NIWA and the University of Waikato, modelled potential diversion scenarios to assess favourable options and ecological impacts. 3-dimensional hydrodynamic modelling showed the longest diversion option would be required to minimise any losses from a plunging underflow current [14]. Hydrodynamic-ecological modelling (DYRESMCAEDYM model) indicated limited change in temperature, dissolved oxygen, nutrients and diatom biomass, but up to a $40 \%$ reduction in summer cyanobacterial chla within four summers [8].

The diversion wall was completed in July 2008 using sheet-piling over a distance of 1275 metres. Lake water quality had been showing some improvements before completion of the diversion wall partly due to a shift in cyanobacteria species from Annabena planktonica and Microcytis aeruginosa to Aphanocapsula holistica a pico-algae.

Since the completion of the wall water clarity has improved slightly as have nitrogen concentrations, leading to an improved TLI resulting in a change to the lake's classification from eutrophic to mesotrophic. Chla and soluble reactive phosphorous (SRP) concentrations did not improve although hypolimnetic volumetric deoxygenation (HVOD) were at levels below those experienced during intensive cyanobacteria blooms in 2002 to 2006 (fig. 2). Although the

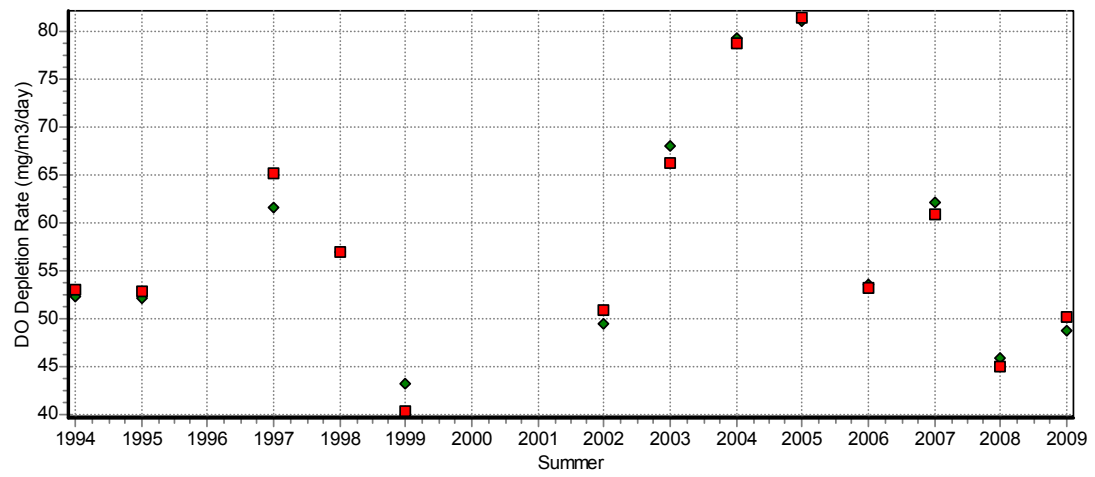

Figure 2: HVOD rates for Lake Rotoiti, 1993 to 2009, squares are HVOD adjusted for standard temperature of $12.3{ }^{\circ} \mathrm{C}$. 
HVOD rates are low it remains to be seen if sediment nutrient release during periods of anoxia will lessen.

\subsection{Other Lake Rotoiti actions}

Upgrading communities from on-site wastewater systems to reticulated centralised sewage treatment has been undertaken for two communities. The community at Okawa Bay has seen the benefits of this action. Okawa Bay is a small shallow embayment on the western side of the lake which underwent anoxic conditions in summer and due to the low exchange rate with the main lake, suffered from severe cyanobacterial blooms.

Removal of an estimated 5.9 tonnes of $\mathrm{N}$ and 0.21 tonnes $\mathrm{P}$ per annum has within two years resulted in a $25 \%$ increase in water clarity. The increase in water clarity has led to a proliferation in the exotic macrophyte Ceratophyllum demersum, with the surface reaching macrophyte being harvested for the first time further reducing the nutrient content of the bay.

Other actions to be taken in the Lake Rotoiti catchment will be dependent on the success of the Ohau Channel diversion wall, which meets the bulk of the catchment nutrient reduction targets. Other potential actions include land management, lake oxygenation, and sediment capping.

\subsection{Lake Rotorua actions}

\subsubsection{Inflows}

Rutherford [12] estimated the nutrient inputs from baseflow data on the nine major inflows. Particulate $\mathrm{P}$ and particulate organic $\mathrm{N}$ loads were shown to increase with increasing flow rates, and Hoare [9] showed that baseflow accounted for greater than $90 \%$ of the nutrient load. With most of the inflow load attributed to soluble nutrients, Rutherford found that $\mathrm{N}$ delivery was increasing with time. Isotopic dating of groundwater inflows [10] showed groundwater ages varying from 15 to 135 years. Increasing nitrate levels can be attributed to increasing agricultural activity following clearance of surrounding lands, and while some catchments will reach equilibrium in 10 to 20 years, it may take up to 100 years for others.

One inflow, the Waiohewa Stream, has a geothermal input at the top of its catchment that has a high concentration of ammonium. A trial nitrificationdenitrification plant is underway to test the efficacy of removing the geothermally sourced ammonium. Nitrification will be undertaken using conventional wastewater technology and denitrification will be via a wood bark or maize cob bed, potentially removing $30 \mathrm{t} \mathrm{N} \mathrm{yr}^{-1}$.

Addressing the increasing nitrate concentrations is not easily achieved by direct intervention of inflows, hence treatment of inflows has predominantly focused on P. Iron, calcium or aluminium salts have been used effectively in flocculation or precipitation of $\mathrm{P}$. Testing of a range of these salts resulted in aluminium sulphate (alum) being applied to one of the major inflows, the Utuhina Stream, binding an estimated $2 \mathrm{t} \mathrm{P} \mathrm{yr}^{-1}$ which settles out in the lake. 
Many of the inflows to the lake are valued trout fisheries, thus treatment of the stream is closely monitored with fish being examined for potential toxicity effects and macroinvertebrate species measured for abundance and diversity. The success of treatment in this stream has led to the possibility of dosing the Puarenga Stream and one other stream potentially locking a total of $6 \mathrm{t} \mathrm{P} \mathrm{yr}^{-1}$.

The greatest $\mathrm{P}$ load enters via the Hamurana Stream $\left(6.3 \mathrm{t} \mathrm{yr}^{-1}\right)$ which also delivers $53 \mathrm{t} \mathrm{yr}^{-1} \mathrm{~N}$, predicted to increase to $92 \mathrm{t} \mathrm{yr}^{-1}$ in 50 years time [3]. Treatment is not economically viable or practicable at this time due to the volume of the stream, but diversion to the Ohau Channel has been considered. However, there are potential cultural, aesthetic and ecological problems that would be encountered by a six kilometre diversion wall. Modelling also indicates that the impact of diverting this inflow would have little impact until the internal nutrient releases are addressed (pers comm. Professor D. Hamilton, University Of Waikato).

\subsubsection{Internal nutrient load}

The legacy of land clearance, the discharge of Rotorua's sewage effluent, rising nutrient levels in inflows, and sedimentation of algal biomass, result in an increased sediment oxygen demand. Lake Rotorua stratifies intermittently in the summer during periods of calm weather leading to enhanced conditions for $\mathrm{P}$ and $\mathrm{N}$ releases. Nutrient releases from the lake bed are the main driver of summer algal productivity in Lake Rotorua.

Burger [1] using benthic chambers and laboratory incubations found high release rates from the lake sediments under variable oxygen conditions, with seasonal means up to $44 \mathrm{mg} \mathrm{m}^{-2} \mathrm{~d}^{-1} \mathrm{SRP}$ and $136 \mathrm{mg} \mathrm{m}^{-2} \mathrm{~d}^{-1} \mathrm{NH}_{4}-\mathrm{N}$. Load calculations estimated sediment release rates of SRP and $\mathrm{NH}_{4}-\mathrm{N}$ at approximately $98 \mathrm{t} \mathrm{N} \mathrm{yr}^{-1}$ and $7.4 \mathrm{t} \mathrm{P} \mathrm{yr}^{-1}$ [3], making it apparent that mitigation of eutrophication will require reducing internal nutrient loads as well as external.

As part of on-going research into remediation of the Rotorua Lakes several sediment capping trials have occurred in two other Rotorua Lakes. Phoslock ${ }^{\mathrm{TM}}$, a bentonite clay with the active ingredient lanthium, has been trialled in Lake Okareka. Greater focus has been on sediment capping trials at the smaller Lake Okaro $\left(0.33 \mathrm{~km}^{2}\right.$, mean depth $\left.12 \mathrm{~m}\right)$, which has had successive treatments, the first being alum $\left(0.6 \mathrm{~g} \mathrm{~m}^{-3}\right)$ followed by repeat applications of a modified zeolite, Z2G1.

Application of the capping medium while the hypolimnion is well oxygenated, precise application techniques, and the best grain size of material to obtain suitable coverage, are some of the lessons learnt [5]. Sequential treatments of Lake Okaro, which include the construction of a wetland to treat the inflowing streams, have resulted in a reduction in the rate of phosphorous release into the hypolimnion over the summer (fig. 3). The continued success of these trials will help determine if use of a sediment capping agent will be applied to Lake Rotorua. Further deliberations and trials of the use of capping agents include economic and ecological aspects of such treatments, and further understanding of their longevity. 


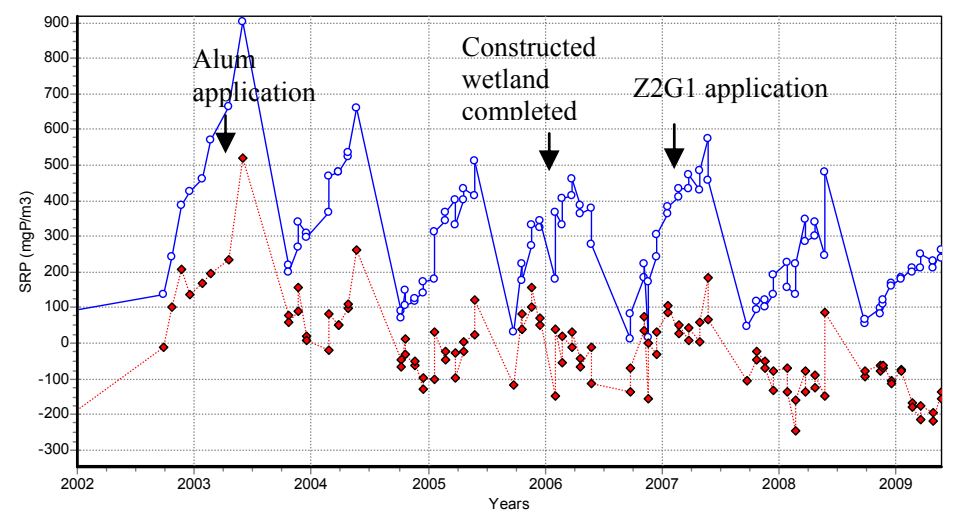

Figure 3: $\quad$ SRP concentration $\left(\mathrm{mg} \mathrm{m}^{-3}\right)$ and deseasonalised residuals (dotted line) in Lake Okaro hypolimnion, 2002 to 2009.

Sediment cores from Lake Rotorua were tested by continuous-flow incubation with four capping agents (alum, Phoslock ${ }^{\mathrm{TM}}, \mathrm{Z} 2 \mathrm{G1}$, and allophane), at a range concentrations [7]. Results indicated capping agents if left undisturbed should continue to adsorb phosphorous for four years. The eutrophic polymictic Lake Rotoehu is being considered for a trial of a capping agent as it has similarities with Lake Rotorua.

Also under consideration are dredging, aeration and ploughing the lakebed. An assessment of dredging to remove the nutrient rich sediments indicates it to be economically unviable. One problem of this remediation option revealed by the analysis of the lakes sediments, found that they are laden with heavy metals from geothermal inputs. Hence disposal or reuse the organic rich sediment is problematic.

Aeration and ploughing are currently being investigated and may provide an alternative to sediment capping or as part of a mixed remediation solution.

\subsubsection{Sewage sources and stormwater}

Treated sewage was diverted from the lake to spray irrigation in a forested section of the Puarenga catchment in the early 1990s. Monitoring of the local streams in this catchment displayed increasing nitrate levels and this finding resulted in improvements being made to the irrigation scheme. Nitrate levels have improved but there are indications that soils may be becoming saturated with respect to phosphorous which will in part be addressed by alum treatment.

An upgrade to the Rotorua Wastewater Treatment Plant has taken place in the form of an additional Bardenpho reactor and methanol injection to increase the carbon to nitrogen ratio to enhance denitrification. These modifications will remove approximately $15 \mathrm{t} \mathrm{N} \mathrm{yr}^{-1}$ from the ultimate nitrogen load leached from the irrigation site.

RDC management initiatives to reduce nutrient contamination of stormwater could reduce $\mathrm{N}$ and $\mathrm{P}$ inputs to the lake by $3 \mathrm{t} \mathrm{yr}^{-1}$ and $0.5 \mathrm{t} \mathrm{yr}^{-1}$ respectively. Initiatives include increased network and gully trap maintenance, street 
sweeping, comprehensive stormwater consents (constraints on permitted discharge standards), increased industrial regulation, and upgrading of trade waste bylaws.

\subsubsection{Land management}

Catchment land use has passed a sustainable limit. This statement is based on the TLI target set by the community in the W\&LP, which balances social and economic benefits of lake water quality with social and economic use of the wider catchment [3]. Without significant $\mathrm{N}$ and $\mathrm{P}$ reduction from land use, lake nutrient targets will not be achieved, hence this is an Action Plan priority.

Land management efforts to reduce nutrient and sediment loads to the lake have been in place since the 1970s. The focus has been on riparian protection, erosion control schemes, land retirement and conversion to forestry blocks. These actions have had some success in limiting total P loads, but have been less successful in limiting nitrate and soluble $\mathrm{P}$. Soluble $\mathrm{P}$ is at elevated concentrations in some spring fed streams due to extraction from the underlying geology and the length of time it takes for water to flow through the aquifers.

The land management working group settled on nutrient reduction targets from catchment land use of $170 \mathrm{t} \mathrm{yr}^{-1}$ and $6 \mathrm{t} \mathrm{yr}^{-1} \mathrm{~N}$ and $\mathrm{P}$ respectively. To limit the further increase of nutrients from diffuse agricultural sources regulation has been set in the W\&LP primarily aimed at properties over 0.4 ha exporting $\mathrm{N}$ loads greater than $10 \mathrm{~kg} \mathrm{ha}^{-1} \mathrm{yr}^{-1}$. Nutrient loss from properties has been capped at $2001-2004$ levels. Land has been benchmarked for this period in consultation with the land owner using modelling tools such as Overseer.

A Sustainable Land Use Implementation Board has been established with the objective of helping achieve the agricultural component of nutrient reduction. Nutrient trading schemes, best nutrient management practice, industry initiatives and directives, new technologies, subdivision, economic incentives, and property purchases are all potential mechanisms used to meet this objective.

Modelling has been undertaken to estimate $\mathrm{N}$ exports from the Rotorua subcatchments. The Rotorua and Taupo Nitrogen model (ROTAN) balances surface and ground water using groundwater mean residence time coupled with land use nutrient export predictions. ROTAN can then be used to run land use change scenarios to predict changes in $\mathrm{N}$ inputs to the lake.

\section{Conclusion}

EnvBOP's lake monitoring regime uses the nutrient status of the lakes, hypolimnetic oxygen depletion, together with their macrophyte and algal conditions in determining lake health. Other factors are also taken into consideration such as, land development intensity, invasive aquatic weeds, lake use intensity and the concerns of local residents.

The major achievement that has enabled effective lake management has been the setting of quantitative limits (TLIs) for the trophic state of the lakes in a statutory document. A rule to limit nutrient loss is triggered if the TLI is 
exceeded and an action plan is required for lake remediation. This policy structure has been enabled by the Resource Management Act (1991).

Two important factors in achieving success in producing and executing proposed and accepted Action Plans are firstly extensive consultation with the people of the Rotorua district and secondly helping these people gain knowledge of basic limnology, particularly the agricultural community. Reduction of inputs from the agricultural sector is essential to meet lake water quality objectives. Many helpful actions from farmers are not mandatory but are carried out voluntarily as their understanding of eutrophication issues grow.

\section{References}

[1] Burger, D.F., Hamilton, D.P., Pilditch, C.A. \& Gibbs, M.M., Benthic nutrient fluxes in a eutrophic, polymictic lake, Hyrobiologia, 584:13-25, 2007.

[2] Burns, N.M., Bryers, G. \& Bowman, E., Protocols for monitoring trophic levels of New Zealand lakes and reservoirs. Published by NZ Ministry for the Environment, Wellington, 2000.

[3] Environment Bay of Plenty, Proposed Lakes Rotorua \& Rotoiti Action Plan. Environment Bay of Plenty, Environmental Publication 2007/11, 2007.

[4] Gibbs, M., Temperature and BOD differentials inshore and offshore in Lake Rotorua near Ohau Channel, Taupo Research Laboratory, DSIR 14: Client Report No, TP64 to Department of Conservation, 1991.

[5] Gibbs, M., Lake Okaro re-treatment with Z2G1 in August 2009, NIWA Client Report: HAM2009-177, 2010.

[6] Gibbs, M., Hawes I. \& Stephens, S., Lake Rotoiti - Ohau Channel: assessment of effects of engineering options on water quality. NIWA Client Report HAM2003-142, 2003.

[7] Gibbs, M., Bremner, D., van Kooten, M. \& Özkundakci, D., Comparison of four P-inactivation agents on Lake Rotorua sediments, NIWA Client Report: HAM2008-105, 2008.

[8] Hamilton, D., McBride, C. \& Uraoka, T., Lake Rotoiti fieldwork and modelling to support considerations of Ohau Channel Diversion from Lake Rotoiti, Centre for Biodiversity and Ecology Research, University of Waikato, 2005.

[9] Hoare, A., The sensitivity to phosphorous and nitrogen of Lake Rotorua, New Zealand, Progress in Water Technology 12: 897-904, 1980.

[10] Morgenstern, U., Reeves, R. Daughney, C. \& Cameron, S., Groundwater age, time trends in water chemistry, and future nutrient load in the lakes Rotorua and Okareka area. Geological \& Nuclear Survey Report 2004/17, 2004.

[11] Nurnberg, G.K., The prediction of internal phosphorous loads in lakes with anoxic hypolimnia, Limnology Oceanography 29:111-124, 1984.

[12] Rutherford, K., Lake Rotorua Nutrient Target Loads, NIWA Client Report HAM2003-155, 2003. 
[13] Scholes P., Rotorua Lakes Water Quality Report 2009. Environment Bay of Plenty, Environmental Publication 2009/12, 2009.

[14] Stephens, S., Modelling the diversion of the Ohau Channel outflow in Lake Rotoiti to the Kaituna River, NIWA Client Report HAM2004-164, 2004.

[15] Vollenweider, R.A., Advances in defining critical loading levels for phosphorous in lake eutrophication, Mem. 1si. Ital. Idrobiol. 33: 53-83, 1976.

[16] Vincent, W.F., Gibbs, M.M., and Dryden S.J. Accelerated eutrophication in a New Zealand lake: Lake Rotoiti, Central North Island. New Zealand Journal of Marine and Freshwater Research 75:431-440.

[17] White P.A., Cameron S.G., Kilgour G., Mroczek E., Bingall G., Daughney C., \& Reeves R.R., Review of Groundwater in the Lake Rotorua Catchment, Institute of Geological \& Nuclear Sciences Client Report 2004/130, 2004. 